\title{
Variabilidade espacial de atributos físicos do solo associados ao uso e ocupação da paisagem ${ }^{1}$
}

\author{
Natalino M. Gomes ${ }^{2}$, Manoel A. de Faria ${ }^{3}$, Antônio M. da Silva ${ }^{3}$, Carlos R. de Mello ${ }^{3}$ \& Marcelo R. Viola ${ }^{4}$
}

\begin{abstract}
RESUMO
O presente trabalho teve-se como objetivo diagnosticar o uso atual das terras e suas implicações na variabilidade espacial dos atributos físicos densidade do solo (Ds), matéria orgânica (MO), frações texturais (areia, silte e argila) e argila dispersa em água ( $\mathrm{ADA}$ ), na bacia hidrográfica do Ribeirão Marcela, Região Alto Rio Grande, MG, através de técnicas de geoestatística, com a finalidade de observar padrões de ocorrência desses atributos na paisagem. Coletaram-se amostras de solo na camada de 0 a 0,15 m em malha, com intervalos regulares de $240 \times 240 \mathrm{~m}$ (macroescala) e de 60 × $60 \mathrm{~m}$ (microescala), totalizando 165 pontos. A Ds apresentou-se com valores na faixa de 1,05 a 1,15 g cm${ }^{-3}$ acima, portando, do valor característico para Latossolos $\left(0,95 \mathrm{~g} \mathrm{~cm}^{-3}\right)$, enquanto os maiores valores foram obtidos nas glebas sob pastejo. Os valores de $\mathrm{MO}$ variaram de 1,5 a 4,5 dag $\mathrm{kg}^{-1}$, detectando-se maiores concentrações nas glebas sob eucalipto, cerrado mais denso e várzeas. As frações texturais variaram seguindo a rede de drenagem e a ADA indicou valores baixos ao longo de toda a bacia. Os mapas de krigagem mostraram-se importante no estudo e compreensão da variabilidade espacial de atributos físicos do solo na bacia hidrográfica, indicando áreas críticas de manejo.
\end{abstract}

Palavras-chave: bacia hidrográfica, krigagem, uso e ocupação do solo

\section{Spatial variability of physical attributes of soil associated with use and occupation of landscape}

\begin{abstract}
This work aimed to diagnose current agricultural soil use as well as its implications for the spatial variability of soil bulk density (Ds), organic matter (OM), particle-size distribution and water dispersible clay (WDC), in Ribeirão Marcela watershed, belonging to Alto Rio Grande region, using geostatistics tools, in order to observe occurrence patterns of these attributes in the landscape. Disturbed and undisturbed soil samples were collected in 0-0.15 m layer, in a grid of $240 \times 240 \mathrm{~m}$ (macro-scale) and $60 \times 60 \mathrm{~m}$ (micro-scale), resulting in 165 samples. Current soil use is not in accordance to soil class agricultural suitability. Soil bulk density presented values between 1.05 and $1.15 \mathrm{~g} \mathrm{~cm}^{-3}$, this range being above characteristic values for Oxisol (close to $0.95 \mathrm{~g} \mathrm{~cm}^{-3}$ ), with the highest values found in lands under pasture. Organic matter values ranges from 1.5 to $4.5 \mathrm{dag} \mathrm{kg}^{-1}$, detecting higher concentrations in lands under eucalyptus, cerrado and wetlands. Particle-size distribution presented behavior following the drainage pathways and WDC presented low values in the entire watershed. Kriging maps were shown to be important tools for the understanding of spatial variability of physical soil attributes in the watershed, indicating critical management areas.
\end{abstract}

Keywords: watershed, kriging, use and occupation of soil

1 Parte da Dissertação de Mestrado do primeiro autor, apresentada a UFLA, com bolsa do CNPq

2 EAFAJT - CP 09. CEP 46.430-000, Guanambi, BA, Distrito de Ceraíma, Zona Rural. Fone: (77) 3459-2100. E-mail: natalagricola@yahoo.com.br

3 DEG/UFLA, CP 3037, CEP 37.200-000, Lavras, MG. Fone: (35) 382-1386. E-mail: mafaria@ufla.br; marciano@ufla.br; crmello@ufla.br, bolsistas do CNPq

${ }^{4}$ Graduando de Engenharia Agrícola, UFLA. Fone: (35) 3826-2927. E-mail: m.r.viola@hotmail.com 


\section{INTRODUÇÃO}

As modernas técnicas de cultivo com mecanização intensa e a elevada taxa de uso dos solos, têm promovido mudanças no comportamento dos seus atributos físicos o que, conseqüentemente, influencia a produção, o equilíbrio dos recursos naturais e a dinâmica da água no solo.

Segundo Bertol et al. (2000) as propriedades físicas do solo precisam ser monitoradas visto que o uso intensivo ou acima da capacidade de suporte pode provocar mudanças indesejáveis, como aumento da densidade do solo (Ds), redução do teor de matéria orgânica (MO), diminuição da porosidade, tamanho de agregados, taxa de infiltração de água e resistência a penetração das raízes (Camargo \& Alleoni, 1997). Souza et al. (2004a, 2001), Eguchi et al. (2002) e Pocay (2000) relatam que as frações texturais são estáveis, ou seja, se modificam pouco ao longo do tempo, apresentando baixo coeficiente de variação.

Trabalhando em um Cambissolo Álico em Santa Catarina, Bertol et al. (2000) verificaram que, com o aumento do teor de MO ocorreu diminuição da Ds e aumento da porosidade e, conseqüentemente, da taxa de infiltração de água no solo. Melo et al. (2001) enfatizam que a MO promove aumento na porosidade total e macroporosidade, diminuição da Ds e aumento na capacidade de retenção de água, quando aplicada em grande quantidade.

No contexto da conservação do solo, a Ds é um dos atributos físicos que mais se destaca em virtude de refletir, especialmente, as condições de compactação do solo, a qual é reflexo do manejo empregado (Dias Júnior, 2000). O aumento do conteúdo volumétrico de sólidos traduz-se em redução drástica na macroporosidade, na quantidade de água prontamente disponível e na aeração (Alvarenga et al., 1996).

Com o auxílio da geoestatística, a estrutura de dependência espacial dos atributos físicos do solo vem sendo intensamente estudada e modelada, permitindo a sua visualização espacial. Souza et al. (2004b) encontraram grau moderado de dependência espacial para todos os atributos texturais de um Latossolo Vermelho Eutroférrico, no estado de SP, sob cultivo de cana-de-açúcar, com alcances do semivariograma esférico na ordem de 230,1, 157,7 e 210,0 m para argila, silte e areia, respectivamente, na camada de 0 a $0,20 \mathrm{~m}$. Trabalhando em um solo aluvial da região de Lavras, MG, Eguchi et al. (2002) relatam dependência espacial para os atributos texturais com alcance dos semivariogramas gaussiano, exponencial e esférico, na ordem de 49,5, 14,5 e 15,0 m para argila, silte e areia, respectivamente. Souza et al. (2001) afirmam moderado grau de dependência espacial para a Ds, com alcances do semivariograma esférico variando de 13,1 a 22,6 m para as camadas de 0 a 0,05 e 0,15 a $0,2 \mathrm{~m}$.

Usualmente, o interesse da análise geoestatística não se limita à obtenção de um modelo de semivariograma e seus parâmetros, desejando-se também predizer valores em pontos não amostrados, sobretudo de atributos que sofrem influência do manejo, caso da matéria orgânica e densidade do solo.
O interesse pode concentrar-se em um ou mais pontos específicos da área ou na obtenção de uma malha de pontos interpolados, de modo a permitir a visualização do comportamento da variável na região, o que é obtido empregandose a interpolação por krigagem. Segundo Gonçalves (1997) e Silva Júnior (1984) este interpolador pondera os vizinhos do ponto a ser estimado, obedecendo aos critérios de não tendenciosidade e mínima variância.

Objetivou-se, neste trabalho, avaliar a variabilidade espacial dos atributos físicos do solo em uma bacia hidrográfica representativa da região Alto Rio Grande, MG, e a correlação dos atributos físicos com práticas de manejo conservacionista dos recursos ambientais, uso atual e aptidão agrícola das terras desta bacia; este enfoque permitirá avaliar a dinâmica de uso e ocupação da paisagem, verificando a possível existência de manejos inadequados do solo, e de fontes potenciais de degradação dos recursos ambientais.

\section{MATERIAL E MÉTODOS}

\section{Descrição geral da área de estudo}

A área de estudo, com aproximadamente 477 ha, compreende a sub-bacia hidrográfica do Ribeirão Marcela, localizada na margem direita do Córrego do Jaguara, que deságua diretamente no reservatório da Usina Hidroelétrica de Camargos/CEMIG, município de Nazareno, Estado de Minas Gerais. Situada entre as coordenadas UTM 550169 e 552810 de longitude W e 7650163 e 7650989 de latitude S e com altitude entre 960 a $1060 \mathrm{~m}$, inserida na Unidade Geomorfológica Planalto dos Campos das Vertentes, Bacia Hidrográfica do Alto Rio Grande.

O clima, segundo a classificação de Köppen, é do tipo Cwa (temperado com verões quentes e úmidos e invernos secos e frios), com os solos, exceto os hidromórficos, sujeitos aos regimes údico e isotérmico (Giarola et al., 1997). O tipo de vegetação dominante é o cerrado tropical subcaducifólio com ocorrências ocasionais de floresta tropical subcaducifólia ou campo de surgente no terço inferior das encostas, campo cerrado tropical nos locais de domínio de solos mais rasos e campo hidrófilo de várzea nas baixadas.

\section{Aptidão agrícola das terras}

As unidades pedológicas presentes na bacia hidrográfica são: Latossolo Variação Una (LU), ocupando cerca de 65\% da área; Latossolo Vermelho Escuro Distrófico (LVEd), 14\%; Cambissolos (C), menos de 5\% e Solos Hidromórficos (Hi), cerca $17 \%$.

A extensão geográfica das unidades de mapeamento de aptidão agrícola e o respectivo percentual da área que ocupam, estão apresentados na Tabela 1, extraídos de (Giarola et al., 1997).

A distribuição das classes de aptidão agrícola das terras da bacia hidrográfica e suas posições na paisagem, encontram-se na Figura 1. A legenda das classes de aptidão agrícola das terras da bacia hidrográfica do Ribeirão Marcela está na Tabela 2. 
Tabela 1. Extensão e distribuição percentual das unidades de mapeamento da aptidão agrícola

\begin{tabular}{|crc|}
\hline Unidade de mapeamento & Área (ha) & Percentual \\
\hline $2(a) b c$ & 14,3274 & 3,0 \\
\hline $2(a) b(c)$ & 21,9687 & 4,6 \\
\hline $2 b c$ & 12,8947 & 2,7 \\
\hline $2(b) c$ & 38,2064 & 8,0 \\
\hline $3(a b)$ & 6,3085 & 1,3 \\
\hline $3(b)$ & 259,3259 & 54,3 \\
\hline $4 p$ & 48,2356 & 10,1 \\
$4(p)$ & 5,7310 & 1,2 \\
\hline $5 n$ & 70,6818 & 24,8 \\
\hline Total & 477,58 & 100,0 \\
\hline
\end{tabular}

Fonte: Giarola et al. (1997)

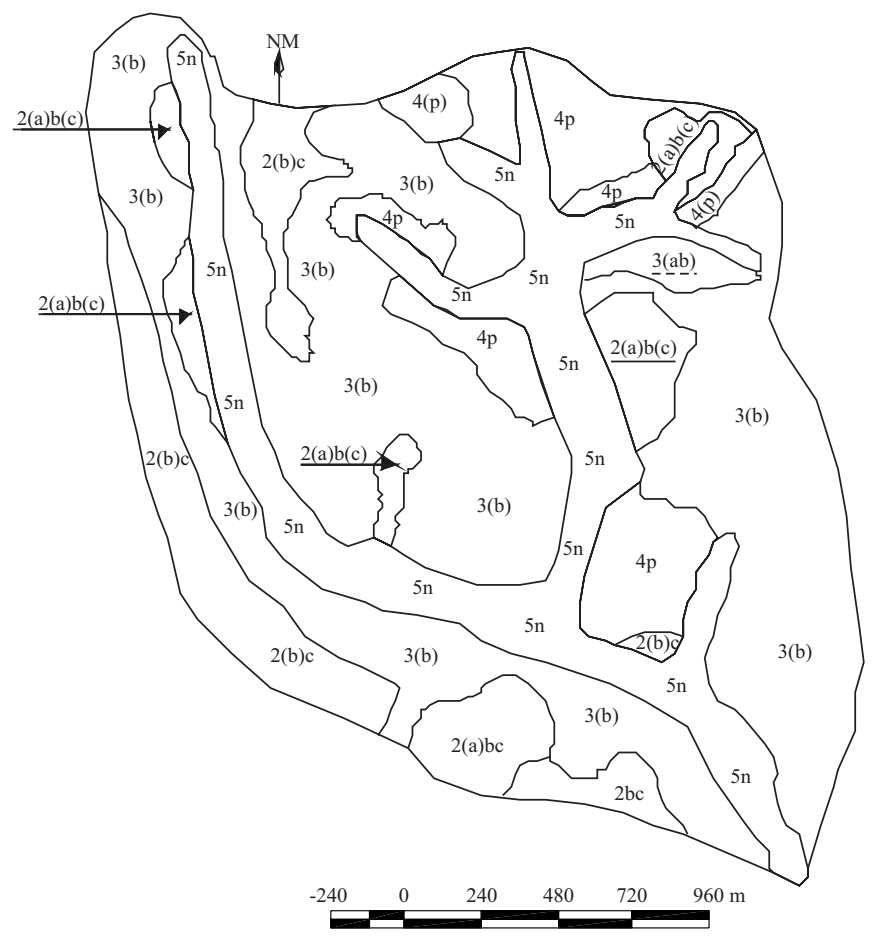

Figura 1. Mapa de aptidão agrícola das terras da bacia hidrográfica do Ribeirão da Marcela, Região Alto Rio Grande, MG

\section{Uso atual das terras}

O uso atual das terras foi avaliado após visitas à bacia hidrográfica, com o auxílio de receptor GPS. De posse dessas informações, os dados foram processados com o auxílio da ferramenta CAD, construindo-se o mapa de uso atual do solo da bacia hidrográfica.

\section{Caracterização física}

As amostras para estudo da variabilidade espacial e estrutura de dependência espacial dos atributos Ds, MO, ADA e frações texturais - areia, silte e argila, foram coletadas na camada de 0 a $0,15 \mathrm{~m}$, obedecendo grid o de 240 x $240 \mathrm{~m}$ (macroescala) e $60 \times 60$ m (microescala), totalizando 165 pontos amostrais, conforme as recomendações de coleta para cada atributo, de acordo com Dias Júnior et al. (2000) e Ferreira et al. (2000). A Ds, ADA e as frações texturais, foram obtidas conforme metodologia proposta por EMBRAPA (1997). O carbono orgânico foi definido através do método do bicromato de sódio $\left(\mathrm{Na}_{2} \mathrm{Cr}_{2} \mathrm{O}_{7} 4 \mathrm{~N}+\mathrm{H}_{2} \mathrm{SO}_{4} 10 \mathrm{~N}\right)$, multiplicando-o pelo fator 1,724 para se obter a percentagem de MO, como descrito por Quaggio et al. (1987).

Tabela 2. Legenda do mapa de aptidão agrícola das terras da bacia hidrográfica do Ribeirão da Marcela, Região Alto Rio Grande

\begin{tabular}{|c|c|}
\hline Simbologia & Descrição \\
\hline $2(a) b c$ & $\begin{array}{l}\text { Terras que pertencem à classe de aptidão restrita para lavouras } \\
\text { no nível de manejo } A \text { e regular nos níveis } B \text { e } C\end{array}$ \\
\hline $2(a) b(c)$ & $\begin{array}{l}\text { Terras que pertencem à classe de aptidão restrita para lavouras } \\
\text { nos níveis de manejo } A \text { e } C \text { e regular no } B\end{array}$ \\
\hline $2 b c$ & $\begin{array}{l}\text { Terras que pertencem à classe de aptidão restrita para lavouras } \\
\text { nos níveis de manejo } A \text { e } C \text { e regular no B }\end{array}$ \\
\hline $2(b) c$ & $\begin{array}{l}\text { Terras que pertencem à classe de aptidão regular para lavouras } \\
\text { no nível de manejo } C \text {, restrita no } B \text { e inapta no } A\end{array}$ \\
\hline $3(a b)$ & $\begin{array}{l}\text { Terras que pertencem à classe de aptidão restrita para lavouras } \\
\text { nos níveis de manejo A e B e inapta no C }\end{array}$ \\
\hline $3(b)$ & $\begin{array}{l}\text { Terras que pertencem à classe de aptidão restrita para lavouras } \\
\text { no nível de manejo B e inapta no } \mathrm{A} \text { e } \mathrm{C}\end{array}$ \\
\hline $4 p$ & $\begin{array}{l}\text { Terras que pertencem à classe de aptidão regular para pastagem } \\
\text { plantada }\end{array}$ \\
\hline $4(p)$ & $\begin{array}{l}\text { Terras que pertencem à classe de aptidão restrita para pastagem } \\
\text { plantada }\end{array}$ \\
\hline $5(n)$ & $\begin{array}{l}\text { Terras com aptidão restrita para silvicultura e/ou pastagem } \\
\text { natural }\end{array}$ \\
\hline & $\begin{array}{l}\text { Traço interrompido sob o símbolo do subgrupo significa que, } \\
\text { dentro da unidade, há terras que apresentam aptidão inferior à } \\
\text { representada no mapa }\end{array}$ \\
\hline
\end{tabular}

Estudo da variabilidade espacial dos atributos físicos do solo

O estudo da dependência espacial por meio do semivariograma experimental isotrópico, a partir da expressão (Journel, 1989) foi:

$$
\gamma^{*}(h)=\frac{1}{2 N(h)} \sum_{i=1}^{N(h)}\left[Z\left(x_{i}\right)-Z\left(x_{i}+h\right)\right]^{2}
$$

em que $\mathrm{N}(\mathrm{h})$ é o número de pares de valores medidos $\mathrm{Z}\left(\mathrm{x}_{\mathrm{i}}\right)$ e $\mathrm{Z}\left(\mathrm{x}_{\mathrm{i}}+\mathrm{h}\right)$, separados por um vetor $\mathrm{h}$. O gráfico de $\gamma^{*}(\mathrm{~h})$ em função dos valores correspondentes de h, chamado semivariograma, é função apenas do vetor h.

Após o cálculo das semivariâncias experimentais os modelos teóricos de semivariogramas, especificamente o exponencial (Eq. 2) e o esférico (Eq. 3), foram ajustados utilizando-se os métodos da máxima verossimilhança (MV) e mínimos quadrados ponderados (MQP), expressos os modelos respectivamente, como:

$$
\begin{aligned}
& \gamma(\mathrm{h})=\mathrm{C}_{0}+\mathrm{C}_{1}\left[1-\exp \left(-3 \frac{\mathrm{h}}{\mathrm{a}}\right)\right] ; \mathrm{a}<\mathrm{h}<\mathrm{d} \\
& \gamma(\mathrm{h})=\mathrm{C}_{0}+\mathrm{C}_{1}\left[\frac{3}{2}\left(\frac{\mathrm{h}}{\mathrm{a}}\right)-\frac{1}{2}\left(\frac{\mathrm{h}}{\mathrm{a}}\right)^{3}\right] ; 0<\mathrm{h}<\mathrm{a}
\end{aligned}
$$

sendo: $\gamma(\mathrm{h})$ a distância máxima em que o semivariograma é definido; $\mathrm{C}_{0}$ - efeito pepita; $\mathrm{C}_{1}$ - variância estrutural e "a" - alcance do semivariograma. 
O grau de dependência (GD), que considera a razão entre a variância estrutural e o patamar, foi utilizado como indicativo de escolha do melhor modelo de ajuste aos dados, conforme sugerido por Robertson (1998). O GD é dado por:

$$
\mathrm{GD}=\left(\frac{\mathrm{C}_{1}}{\mathrm{C}_{1}+\mathrm{C}_{0}}\right) \times 100
$$

além disto, a técnica da validação cruzada (“cross validation”), apresentada por Vieira et al. (1981), também foi aplicada para o estudo do melhor modelo de ajuste aos dados e método de semivariograma, segundo sugestão de Isaaks \& Srivastava (1989) e Cressie (1991). Nesta técnica, cada ponto medido é excluído e seu valor é estimado com os dados restantes (Vieira, 1997; 1998), ou seja, estima os valores da variável em estudo sobre os mesmos pontos amostrados e compara os novos valores com os dados medidos; este procedimento foi realizado com base nos modelos de semivariograma e métodos de ajuste utilizados, uma vez que a krigagem está fortemente associada ao modelo de semivariograma escolhido, permitindo que a validação cruzada possa ser usada para se verificar a precisão do modelo e o método de semivariograma a ser adotado (Vieira et al., 1981).

O programa GeoR foi aplicado em todas as análises do presente trabalho seguindo-se instruções de Ribeiro Júnior \& Diggle (2001) e Mello (2004).

\section{RESULTADOS E DISCUSSÃO}

\section{Uso atual e aptidão agrícola dos solos}

Atualmente, percebe-se pequena diversidade de uso nas terras da bacia hidrográfica, destacando-se pastagem, 75,87\% das terras da bacia hidrográfica, principalmente a natural, de baixa capacidade de suporte, apresentando variação da qualidade do pasto ao longo do ano; entretanto, se observam outros usos, mas com menor expressão quando comparados com a atividade pecuária leiteira; este fato permite inferir que as terras estão subutilizadas haja vista que, aproximadamente 73\% da área da sub-bacia apresentam aptidão para a lavoura em pelo menos um dos três níveis de manejo (Figura 1 e Tabela 1); hoje apenas 17,37\% (Figura 2 e Tabela 3) estão sendo utilizados com esta atividade. A Tabela 3 traz a ex-

Tabela 3. Extensão e distribuição percentual das unidades de mapeamento

\begin{tabular}{lcc}
\hline Unidade de mapeamento & Área (ha) & Percentual (\%) \\
Pastagem natural e plantada & 362,36 & 75,87 \\
Cultura de milho & 79,73 & 16,69 \\
Fragmentos de mata natural & 19,83 & 4,15 \\
Eucaliptal & 9,13 & 1,92 \\
Lago & 3,27 & 0,68 \\
Cultura de maracujá & 1,73 & 0,36 \\
Canavial & 1,53 & 0,33 \\
Total & 477,58 & 100 \\
\hline
\end{tabular}

tensão geográfica do mapeamento de uso atual e o respectivo percentual da área total ocupado por cada atividade na sub-bacia hidrográfica.

A Figura 2 mostra a rede de drenagem e as respectivas posições que as atividades ocupam no solo da bacia hidrográfica. Analisando-se as Figuras 1 e 2 (aptidão x uso atual), a primeira informação que se obtém é que o uso e a ocupação das terras não estão em conformidade com as classes de aptidão, o que pode estar provocando a degradação e subutilização do solo na bacia hidrográfica.

Práticas de manejo conservacionistas, como plantio em nível, terraços, cordões de isolamento, bacias de contenção e rotação do pastejo, dentre outras, não foram observadas, e se pôde verificar a adoção de queimadas, como prática para limpeza das pastagens depauperadas; esta constatação permite inferir que, além da subutilização em que as terras se encontram, os agricultores que nelas trabalham contribuem paulatinamente para a degradação do ambiente, o que reflete a falta de informação e o seu baixo nível de consciência.

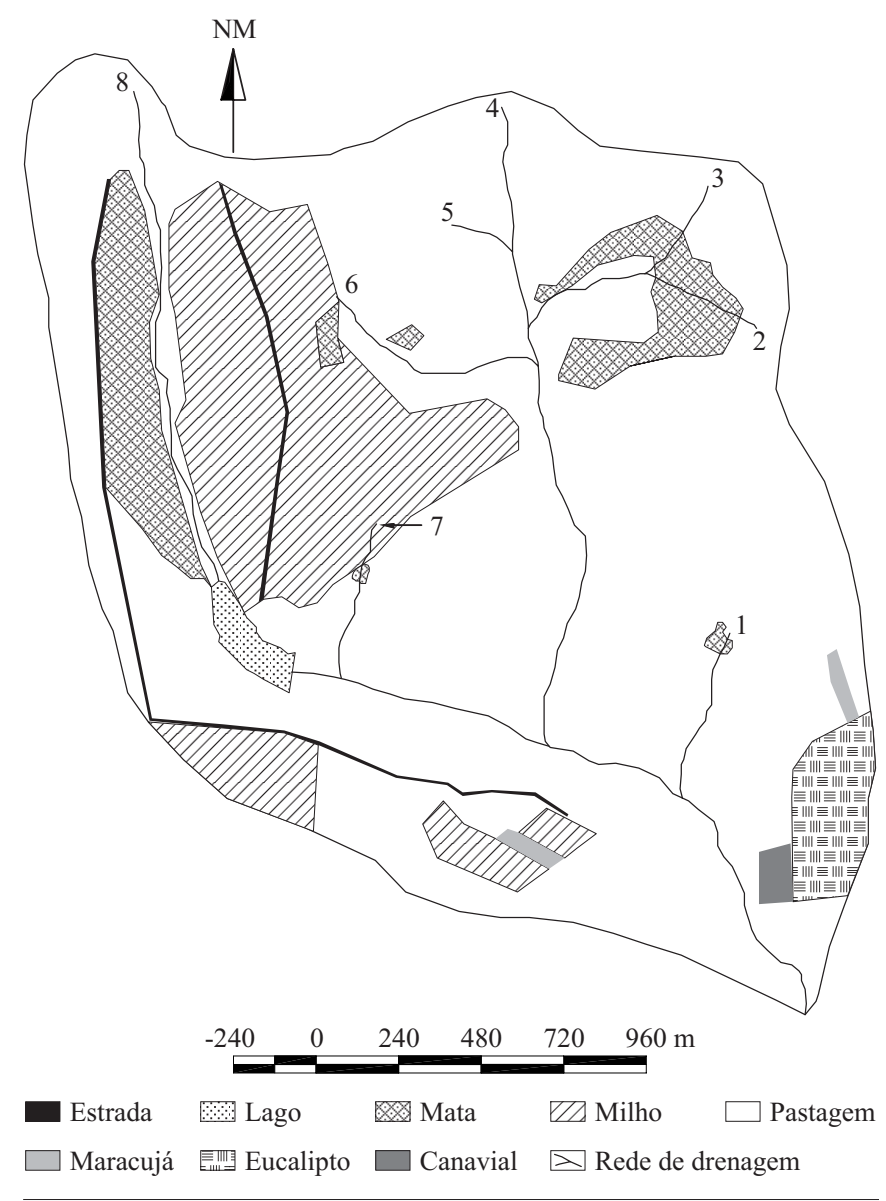

Figura 2. Mapa de ocupação e uso atual do solo na bacia hidrográfica do Ribeirão da Marcela, Região Alto Rio Grande, MG

Durante a fase de campo do estudo, detectou-se avançado estado de degradação de algumas partes da pastagem, o que se caracteriza pela presença de “pelados”, áreas com pouca cobertura vegetal e sulcos de erosão, embora rasos, mas com elevada freqüência.

Outro fato que merece destaque é a inexistência de mata 
ciliar ao longo da rede de drenagem e pouca cobertura vegetal nas proximidades das nascentes, restringindo-se à presença de pequenos fragmentos (Figura 2). Visualiza-se, na área de recarga de duas nascentes, uma lavoura de milho na qual não se constatou adoção de práticas de manejo conservacionista (terraços, plantio em nível e cordões de isolamento, dentre outras), o que pode ser um indício de que essas nascentes estão sendo assoreadas e até mesmo contaminadas diretamente com agroquímicos carreados pelas enxurradas. Com relação às nascentes inseridas em meio à pastagem, detecta-se que elas sofrem diretamente as conseqüências do pastejo em seu entorno, haja vista o pisoteio do gado e a utilização de seus próprios "olhos e/ ou minadouros”, como bebedouros, o que seria facilmente corrigido cercando-se a área adjacente. O gado pode estar compactando o solo da área de recarga, o que dificultará, sem dúvida, a recarga de aqüíferos, favorecendo o escoamento superficial e a produção de sedimentos, contribuindo diretamente com o assoreamento dos corpos receptores em função dos sedimentos transportados.

É de se esperar, portanto, que a dinâmica de uso e ocupação do solo afete a variabilidade de alguns atributos físicos do solo principalmente daqueles que herdam influência do manejo, caso da Ds e MO.

\section{Ajuste e seleção de semivariogramas}

A Tabela 4 mostra os parâmetros obtidos para modelos de semivariogramas e os métodos de ajuste que apresentaram os maiores graus de dependência. Não há predominância entre os modelos de semivariogramas; ambos podem ser empregados no estudo da variabilidade espacial dos atributos físicos do solo. Com relação ao método de ajuste, nota-se predominância da MV, exceção feita à MO, na qual o GD obtido pelo semivariograma esférico ajustado por MQP se destacou dos demais. De maneira geral, o baixo valor do efeito pepita $\left(\mathrm{C}_{0}\right)$ encontrado para todos os atributos, quando comparado ao patamar $\left(C_{0}+C_{1}\right)$, mostra a forte estrutura de dependência espacial dos atributos, sendo a exceção a Ds, a qual indicou moderada estrutura de dependência espacial.

Tabela 4. Modelos de semivariogramas ajustados aos atributos densidade do solo (Ds), matéria orgânica (MO), areia, silte, argila e argila dispersa em água (ADA) com os maiores graus de dependência espacial

\begin{tabular}{llccccc}
\hline \multirow{2}{*}{ Atributo } & \multirow{2}{*}{ Modelo } & \multirow{2}{*}{ Método } & \multicolumn{4}{c}{ Parâmetros } \\
\cline { 4 - 7 } & & $\mathbf{C}_{\mathbf{0}}$ & $\mathbf{C}_{\mathbf{0}}+\mathbf{C}_{1}$ & $\mathbf{a}$ & GD \\
Ds & Esférico & MV & 0,0071 & 0,0103 & 425,90 & 0,5920 \\
M0 & Esférico & MQP & 0,0846 & 0,9166 & 354,08 & 0,9155 \\
Areia & Exponencial & MV & 11,090 & 58,79 & 3000,00 & 0,8413 \\
Silte & Exponencial & MV & 4,050 & 16,99 & 291,48 & 0,8075 \\
Argila & Exponencial & MV & 25,990 & 61,56 & 1236,63 & 0,7031 \\
ADA & Esférico & MV & 2,920 & 21,88 & 193,440 & 0,8822 \\
\hline
\end{tabular}

MV - máxima verossimilhança; MQP - mínimos quadrados ponderados; $\mathrm{C}_{0}$ - efeito pepita; $\mathrm{C}_{0}+\mathrm{C}_{1}$ - patamar; a - alcance; GD - grau de dependência espacial

Os resultados da validação cruzada estão na Tabela 5, ou seja, os valores de erros médio e máximo, e o quadrado médio do erro, obtidos com a comparação dos valores preditos pela krigagem nos pontos de coleta com os medidos no campo.
Confrontando-se os resultados das Tabelas 4 e 5, percebe-se que para os atributos Ds e argila, os modelos que apresentaram os maiores graus de dependência, não tiveram, portanto, o mesmo desempenho na validação cruzada. De maneira geral não há, entre os modelos (esférico e exponencial) um que se destaque em relação ao outros, porém, Mello (2004) comenta que o modelo exponencial deve ser o escolhido uma vez que sua estrutura matemática é menos complexa. Com relação ao método de ajuste, observaram-se mudanças de métodos para os atributos MO e areia, mas, se nota claramente, que o método MV se destaca; contudo, o método MQP, pelos resultados encontrados, foi o ajuste indicado apenas para a fração textural areia, enquanto os modelos indicados pela validação cruzada foram utilizados no processo de interpolação por krigagem para obtenção dos mapas de superfície para os atributos, possibilitando a visualização da sua variabilidade espacial na bacia hidrográfica.

Tabela 5. Resultado da validação cruzada para os modelos de semivariogramas e métodos de ajuste que proporcionaram os menores erros aos atributos densidade do solo (Ds), matéria orgânica (MO), areia, silte, argila e argila dispersa em água (ADA)

\begin{tabular}{llcccl}
\hline Atributo & Modelo & Método & EM (\%) & EMA (\%) & QME \\
Ds & Exponencial & MV & 7,02 & 26,66 & 0,008547 \\
M0 & Esférico & MV & 20,00 & 97,20 & 0,1916 \\
Areia & Exponencial & MQP & 17,02 & 60,61 & 0,9400 \\
Silte & Exponencial & MV & 17,60 & 162,26 & 0,7358 \\
Argila & Esférico & MV & 7,79 & 32,190 & 0,5700 \\
ADA & Esférico & MV & 36,32 & 225,76 & 2,0078 \\
\hline
\end{tabular}

MQP - mínimos quadrados ponderados, MV - máxima verossimilhança; EM - erro médio, EMA - erro máximo e QME - quadrado médio da estimativa do erro

\section{Variabilidade espacial dos atributos físicos do solo}

Apresentam-se, na Figura 3, os mapas de superfície dos atributos físicos Ds, MO, areia, silte, argila e ADA na bacia hidrográfica. Pela gradação dos tons de cinza, nota-se grande variabilidade para os atributos estudados ao longo da extensão geográfica da bacia e, confrontando-se as Figuras 2 (uso atual) e 3A (variabilidade da Ds), nota-se menores valores da Ds nas glebas cultivadas com lavouras e eucalipto $\left(1,05 \mathrm{~g} \mathrm{~cm}^{-3}\right)$, constando-se o contrário nas glebas ocupadas com pastagens $\left(1,15 \mathrm{~g} \mathrm{~cm}^{-3}\right)$. O valor característico para este atributo nos Latossolos, segundo Camargo \& Alleoni (1997), encontra-se próximo de $0,95 \mathrm{~g} \mathrm{~cm}^{-3}$, o que confirma a compactação atual dos solos em toda a bacia, principalmente nas glebas sob pastejo, cujo resultado previsto, uma vez que inúmeros estudos comprovaram que o pisoteio promovido pelo gado é um dos principais agentes causadores da compactação do solo nesta região. Segundo Bertol et al. (2000), o manejo dos animais sobre as pastagens causa modificações nas propriedades físicas do solo, a médio e longo prazos, em que as pressões aplicadas pelo pisoteio dos animais ocasionam alterações na densidade e na porosidade do solo, principalmente nos primeiros 0,03 a $0,06 \mathrm{~m}$ de profundidade.

No lado oeste, região de várzea, seguindo o curso d’água principal, notam-se menores valores para a Ds, explicado em 
A.

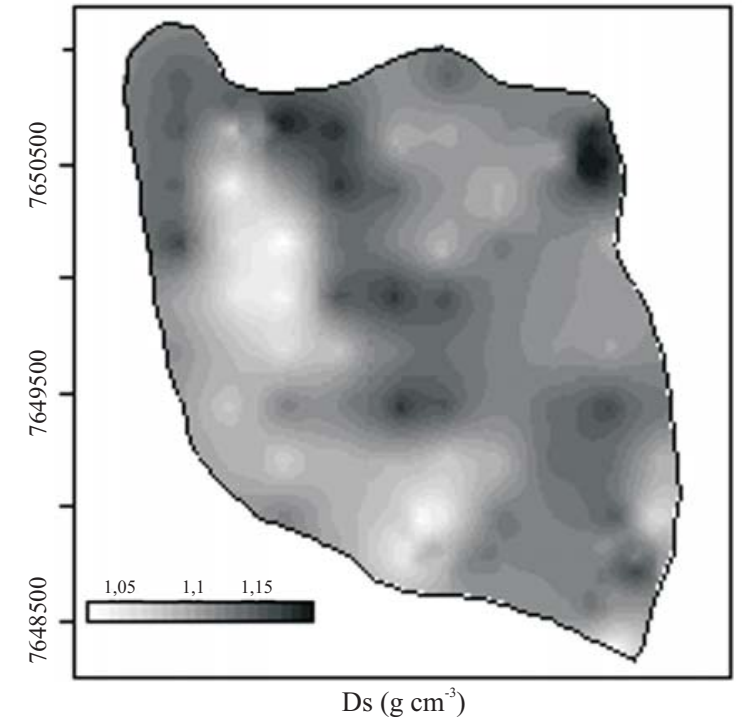

C.

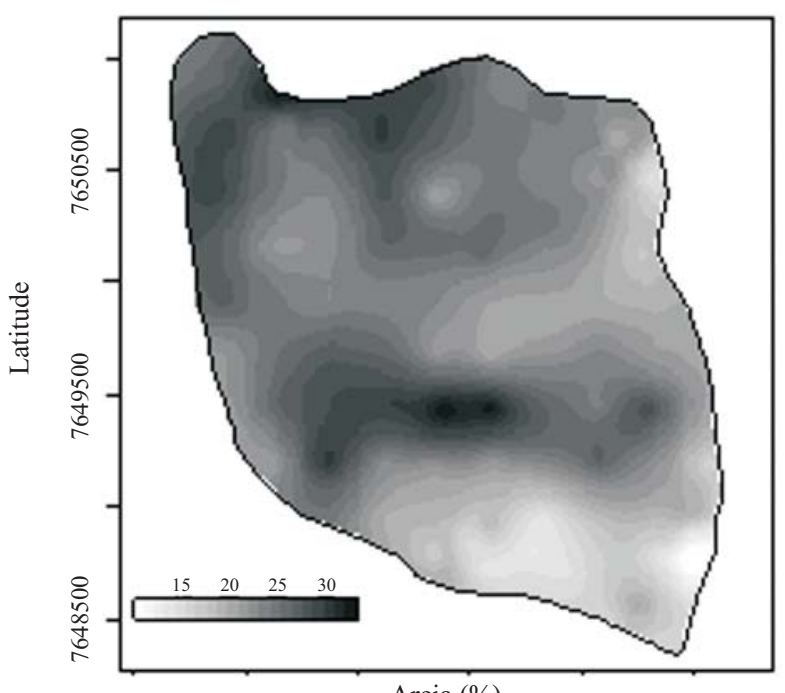

E.

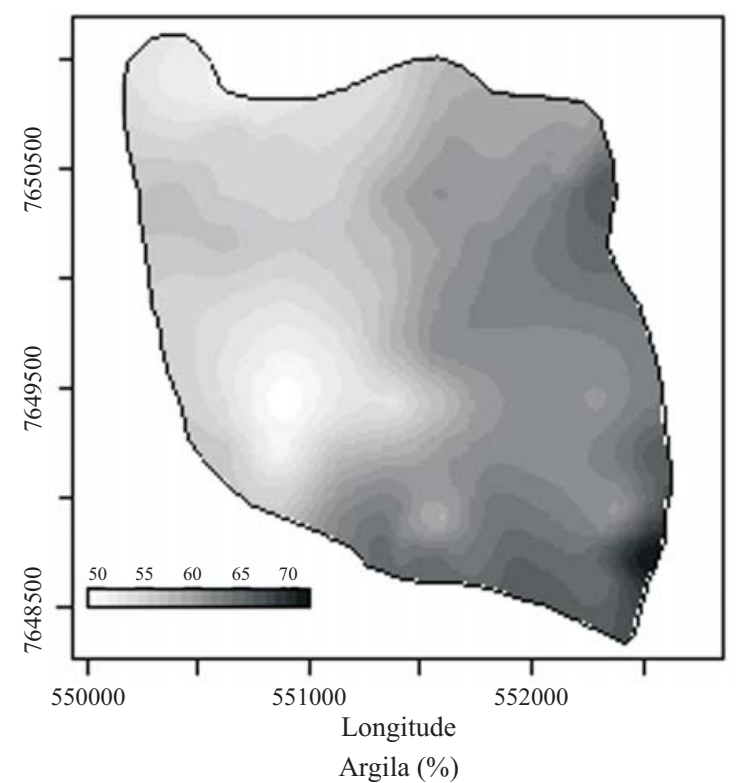

B.

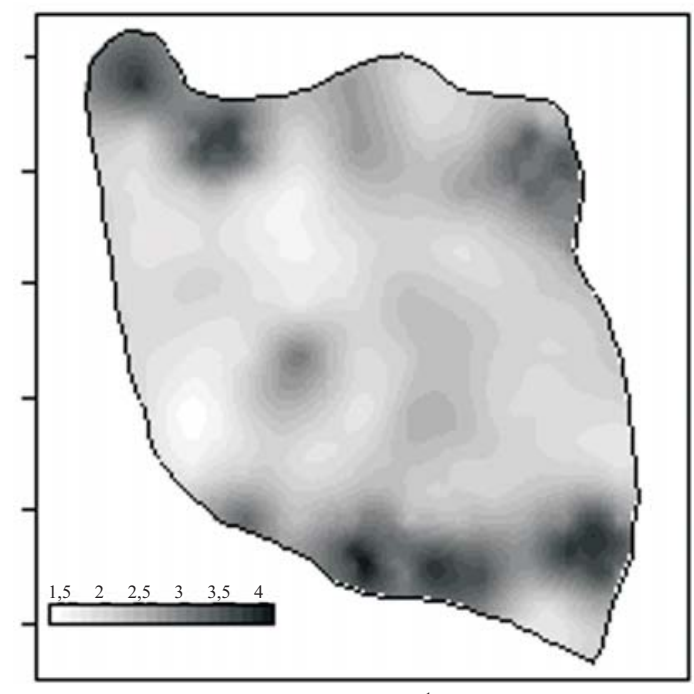

$\mathrm{MO}\left(\mathrm{dag} \mathrm{kg}^{-1}\right)$

D.

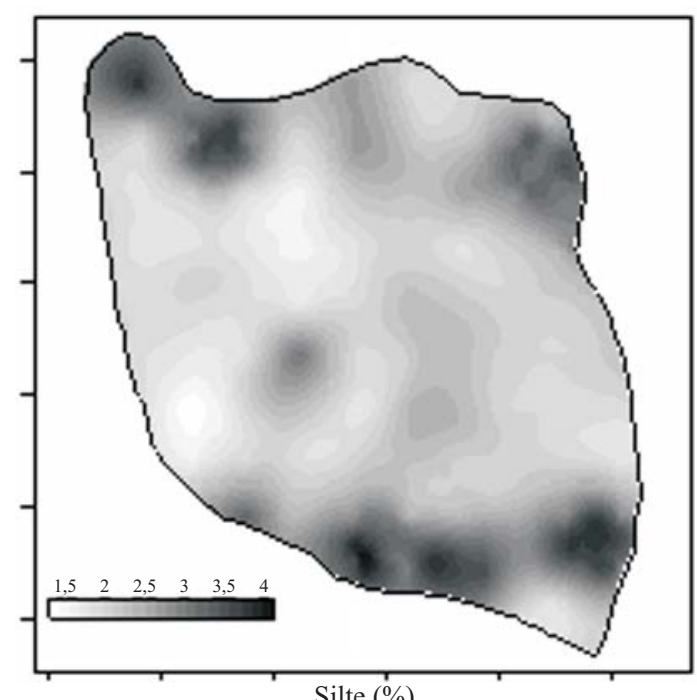

F.

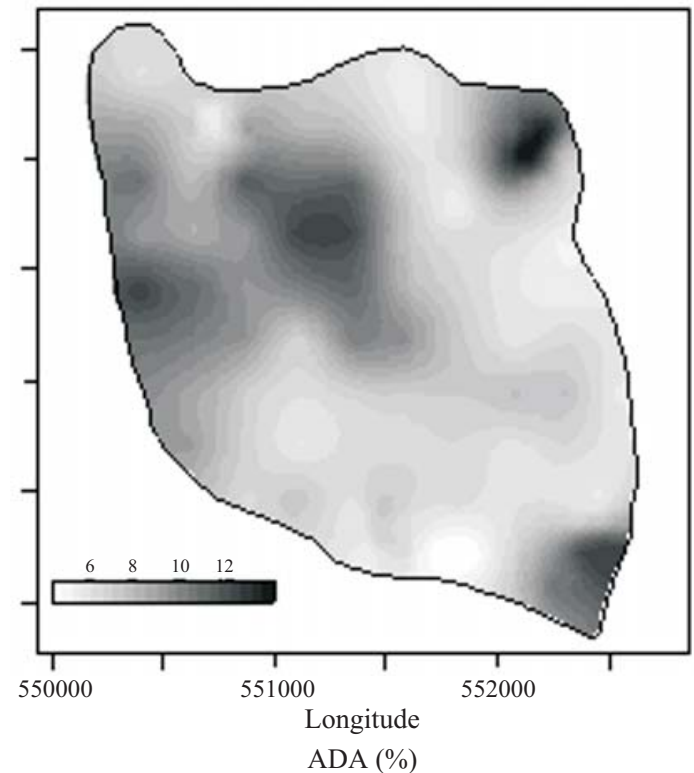

Figura 3. Distribuição espacial das variáveis A) Ds, B) $M O, C$ ) areia, D) silte, E) argila e F) ADA, na profundidade de 0-0,15 m na bacia hidrográfica do Ribeirão Marcela, Região Alto Rio Grande, MG 
função do acúmulo natural de matéria orgânica, devido ao ambiente redutor, o que retarda e dificulta a mineralização da matéria orgânica, fato ainda observado próximo à seção de controle, ao sul da bacia hidrográfica.

A região, situada na parte superior esquerda da bacia (cultivada atualmente com milho) apresenta menores valores de Ds quando, no entanto, se supunha o oposto, em razão do tráfego de máquinas para as operações agrícolas; o fato se deve ao pouco tempo de cultivo de vez que, segundo relatos dos próprios agricultores, esta gleba se encontrava sob vegetação natural (cerrado) até o ano 2000, sendo eventualmente pastejada, passando a ser explorada para o cultivo mecanizado de culturas anuais a partir deste ano.

Constata-se, pela Figura 3A, a presença de manchas escuras (indicativas de maior Ds) nas regiões de recarga de algumas nascentes, indicando perturbação das condições de infiltração e restrição ao fluxo de água no solo, podendo comprometer o abastecimento do lençol, em virtude de favorecer o escoamento superficial; deste modo, possibilita o arraste de partículas, promove o assoreamento dos corpos d’água e nascentes, aumentando a resistência mecânica à penetração radicular e, assim, contribui para reduzir a aeração e disponibilidade de água às plantas (Camargo \& Alleoni, 1997).

Com relação à MO (Figura $3 \mathrm{~B}$ ) percebe-se uniformidade com manchas indicativas de maiores percentuais isolados ao norte e sul, no sentido leste-oeste. Na região sudeste se localiza a gleba ocupada com eucalipto e, a sudoeste, um cerrado denso e pouco pastejado; em ambas as situações, há condições favoráveis ao acúmulo de serapilheira (acúmulo de palha matéria orgânica sobre a superfície) culminando com maior percentual de MO detectado pelas análises e indicado pela krigagem, o que evidencia o provável efeito benéfico da matéria orgânica na redução da Ds.

O fato da bacia ser ocupada, na sua maior parte, por pastagem, explica a uniformidade dos percentuais de matéria orgânica encontrados (1,5 a 2,5 dag $\mathrm{kg}^{-1}$ ). De acordo com Moraes et al. (2003), a presença da matéria orgânica é de suma importância, uma vez que atenua o impacto das gotas de chuva, evitando a compactação e o salpicamento do solo, altera a distribuição de poros, facilitando a infiltração de água no solo, além de criar condições favoráveis ao desenvolvimento da macro e microfauna, aumentando a capacidade de retenção e o armazenamento de água pelo solo. Marciano et al. (2001) relatam que, quando o solo possui, originalmente, uma boa estrutura (caso dos Latossolos), pode não ocorrer melhorias nos atributos físicos, mesmo com a presença de grandes quantidades de MO, sobretudo em variáveis que apontam grande variabilidade espacial.

Esses fatos corroboram a hipótese de que a densidade do solo e o teor de matéria orgânica herdam influência do manejo empregado no uso e ocupação das terras, razão por que tais atributos podem ser considerados bons indicadores das condições de uso, ocupação e equilíbrio dos recursos presentes nas bacias hidrográficas.
A variabilidade espacial das frações texturais (areia, silte e argila) pode ser visualizada nas Figuras 3C, D e E. Depreende-se que o maior percentual de areia se encontra ao norte e a leste da bacia, atingindo a concentração máxima no centro da mesma, margeando a rede de drenagem. Provavelmente a mancha escura observada no centro se deve ao fato dela se situar nas proximidades de encontro dos dois principais corpos d'água da bacia, o que pode ser notado confrontando-se as Figuras 2 e 3C. Próximo à seção de controle se detecta baixo percentual de areia ( 15\%), fato este justificado pela dificuldade de arraste desta partícula através de enxurradas, em função da sua maior densidade, concordando com Telles (1988), que relata que, quando ocorrem grandes chuvas, as águas estão sempre carregadas de elementos em suspensão e, quando extravasam, abandonando a calha, perdem a capacidade de transporte e passam a depositá-los. Esta sedimentação se faz de maneira bem regular, seguindo-se as leis da física de deposição em dois sentidos; na vertical e na horizontal; assim, as areias se apresentam concentradas mais próximas ao leito dos rios e aos locais de origem, enquanto as partículas finas, como silte e argila, são arrastadas por distâncias maiores (Carvalho, 1994).

A fração silte não apresenta grandes variações no seu percentual ao longo da bacia (15 a 20\%), visualizando-se pequenas manchas com $25 \%$ nas direções norte, sudeste e sudoeste. Esta fração, em função de sua instabilidade, é pouco desejável, visto que é a primeira a se desprender pela ação das gotas de chuva, e a principal fração a ser arrastada, causando o assoreamento de rios e lagos. Nas glebas em que se constata sua maior presença, deve-se proteger melhor o solo, mantendo-o com cobertura mais densa e se adotando práticas conservacionistas, tais como terraços, cordões de isolamento, bacias de contenção e outras.

A classe textural de um solo pode ser indicativa do seu potencial de uso pois, de maneira geral, solos argilosos tendem a apresentar elevada capacidade de troca catiônica (CTC), o que é garantia de bom suprimento nutricional às plantas e também elevada microporosidade, o que ajuda a aumentar a capacidade de retenção e armazenamento de água; isto significa que solos argilosos (caso da bacia hidrográfica) levarão mais tempo para terem seu armazenamento de água esgotado, quando comparados com solos arenosos, oferecendo boas condições de suprimento hídrico às plantas, e reforçando a aptidão agrícola das terras da bacia.

A bacia, como um todo, apresenta baixo grau de dispersão da fração argila (5 a 20\%) (Figura 3F), quando comparada com a encontrada por Paiva et al. (2002) para o horizonte Ap de um Latossolo Amarelo argissólico (56\%); este resultado permite inferir que a bacia apresenta pouco material disponível para ser arrastado pela água, ou seja, material com considerável resistência à ação mecânica das gotas de chuva (dispersão e salpicamento); contudo, ressalta-se que o estado em que se encontram os solos (elevada Ds e falta de cobertura vegetal) favorece o escoamento superficial e potencializa a erosão e o carreamento de partículas, não refletindo sua resistência esperada. 


\section{CONCLUSÕES}

1. Verifica-se que o manejo, o uso e a ocupação do solo atuais, não consideram a aptidão agrícola na bacia hidrográfica do Ribeirão da Marcela.

2. As terras estão subutilizadas, uma vez que poderiam estar ocupadas com pastagem de melhor qualidade e maior capacidade de suporte ou serem agricultadas com culturas anuais, de rápido retorno de capital.

3. A densidade do solo apresentou valores acima do previsto para a classe dos Latossolos em toda a extensão da bacia hidrográfica, variando em função da ocupação do solo.

4. O teor de MO variou pouco na bacia, em função de ser quase toda ocupada com pastagem, mas se detectou maior percentual em glebas ocupadas com eucalipto e cerrado mais denso.

5. O estudo da variabilidade espacial de atributos físicos do solo pela geoestatística, utilizando-se a técnica da krigagem, mostrou-se uma importante ferramenta na compreensão da dinâmica dos solos, podendo ser fundamental no auxílio à tomada de decisões que visem maior longevidade e melhor gestão dos recursos.

\section{LITERATURA CITADA}

Alvarenga, C. R.; Costa, L. M.; Moura Filho, W.; Regazzi, A. J. Crescimento de raízes de leguminosas e camadas de solo compactadas artificialmente. Revista Brasileira de Ciência do Solo, Campinas, v.20, n.2, p.319-326, 1996.

Bertol, I.; Almeida, J. A. de; Almeida, E. X.; Kurtz, C. Propriedades físicas do solo relacionadas a diferentes níveis de oferta de forragem de capim-Elefante-Anão cv. Mott. Pesquisa Agropecuária Brasileira, Brasília, v.35, n.5, p.10471054, 2000.

Camargo, O. T. de; Alleoni, L. R. F. Compactação do solo e o desenvolvimento das plantas. Piracicaba: ESALQ/USP. 1.ed. 1997. 132p.

Carvalho, N. O. Hidrossedimentologia prática. Rio de Janeiro: CPRM, 1994. 372p.

Cressie, N. Statistics for spatial data. New York: John Wiley, 1991. 900p.

Dias Júnior, M. de S. Compactação do solo. In: Novais, R. F.; Alvarez V. V. H.; Schaefer, C. E. G. R. Tópicos em ciência do solo. Viçosa: SBCS, 2000. cap.2, p.55-94.

Dias Júnior, M. de S.; Bertoni, J. C.; Bastos, A. R. R. Física do solo: Curso de Pós-Graduação em Solos e Nutrição Mineral de Plantas. Lavras: UFLA, 2000. 147p. Notas de aulas teóricas.

Eguchi, E. S.; Silva, E. L. da; Oliveira, M. S. de. Variabilidade espacial da textura e da densidade de partículas em um solo aluvial no Município de Lavras, MG. Revista Brasileira de Engenharia Agrícola e Ambiental, Campina Grande, v.6, n.2, p.242-246, 2002.

EMBRAPA - Empresa Brasileira de Pesquisa Agropecuária. Centro Nacional de Pesquisa de Solos. Manual de métodos de análise de solo. 2.ed. Rio de Janeiro: Ministério da Agricultura e Abastecimento. 1997. 212p.
Ferreira, M. M.; Dias Júnior, M. S.; Bertoni, J. C.; Bastos, A. R. R. Física do solo: Curso de Pós-Graduação em Solos e Nutrição Mineral de Plantas. Lavras: UFLA, 2000. 33p. Notas de aulas práticas.

Giarola, M. F. B.; Curi, N.; Siqueira, J. O.; Chagas, C. S.; Ferreira, M. M. Solos da região sob influência do reservatório da hidrelétrica de Itutinga/Camargos (MG): Perspectiva ambiental. Lavras: UFLA, 1997. 101p. Convênio CEMIG/UFLA/FAEPE.

Gonçalves, A. C. A. Variabilidade espacial de atributos físicos do solo e resposta espectral da cultura de feijão irrigado, em imagens aéreas digitais. Piracicaba: ESALQ/USP. 1997. 118p. Tese Doutorado

Isaaks, E. H; Srivastava, R. M. Applied geoestatistic: Na introduction to. New York: Oxford University Press, 1989. 561p.

Journel, A. G. Fundamentals of geoestatístics in five lessons. Washington: American Geophysical Union, 1989. 40p.

Marciano, C. R.; Moraes, S. O.; Oliveira, F. C.; Matiazzo, M. E. Efeito do lodo de esgoto e do composto de lixo urbano sobre a condutividade hidráulica de um Latossolo Amarelo saturado e não saturado. Revista Brasileira de Ciência do Solo, Viçosa, v.25, n.1, p.1-9. 2001.

Mello, J. M. de. Geoestatística aplicada ao inventário florestal, Piracicaba: ESALQ/USP, 2004. 110p. Tese Doutorado

Melo, W. J.; Marques, M. O.; Melo, V. P. O uso agrícola e as propriedades do solo. In: Tsutiya, M. T.; Comparini, J. B.; Alem Sobrinho, P.; Hespanhol, I.; Carvalho, P. de. C. T. de; Melfi, A. J.; Melo, W. J. de.; Marques, M. O. Biossólido na agricultura. São Paulo: Companhia de Saneamento do Estado de São Paulo, 2001, p.289-363.

Moraes, J. M.; Schuler, A. E.; Guandique, M. E. G.; Milde, L. C.; Groppo, J. D.; Martilelli, A. L.; Victoria, R. L. Propriedades físicas dos solos na parametrização de um modelo hidrológico. Revista Brasileira de Recursos Hídricos, Porto Alegre, v.8, n.1, p.61-70, 2003.

Paiva, A. de Q.; Souza, L. da S.; Ribeiro, A. C.; Costa, L. M. da. Propriedades físico-hídricas de solos de uma toposseqüência de tabuleiro do estado da Bahia. Pesquisa Agropecuária Brasileira, Brasília, v.35, n.11, p.2295-2302, 2002.

Pocay, V. G. Relações entre pedoforma e variabilidade espacial de atributos de Latossolo sob cultivo intensivo de cana-deaçúcar. Jaboticabal: FCAV/UNESP. 2000. 177p. Dissertação Mestrado

Quaggio, J. A.; Cantarella, H.; Ferreira, M. E.; Lopes, A. S.; Bataglia, O. C. Análise química do solo. Campinas: Fundação Cargil, 1987. 170p.

Ribeiro Júnior, P. J.; Diggle, P. P. Geor: A package for geostatistical analysis. R-News, v.1, n.2, p.15-18, 2001.

Robertson, G. P. GS ${ }^{+}$; Geostatistics for the environmental sciences - GS ${ }^{+}$User's Guide. Plainwell: Gamma Design Soffware, 1998. 152p.

Silva Júnior, M. C. Composição florística, estrutura e parâmetros fitossociológicos do cerrado e sua relação com o solo na Estação Florestal de Experimentação de Paraopeba, MG. Viçosa: UFV, 1984. 130p. Dissertação Mestrado

Souza, Z. M.; Marques Júnior, J.; Pereira, G. T.; Barbieri, D. M. Variabilidade espacial da textura de um Latossolo Vermelho eutroférrico sob cultivo de cana-de-açúcar. Engenharia Agrícola, Jaboticabal, v.24, n.2, p.309-319, 2004a. 
Souza, Z. M.; Marques Júnior, J.; Pereira, G. T. Variabilidade espacial da estabilidade de agregados e matéria orgânica em solos de relevos diferentes. Pesquisa Agropecuária Brasileira, Brasília, v.39, n.5, p.491- 499, 2004b.

Souza, Z. M.; Silva, M. L. S.; Guimarães, G. L.; Campos, D. T. S.; Carvalhos, M. P.; Pereira, G. T. Variabilidade espacial de atributos físicos em m Latossolo Vermelho Distrófico sob semeadura direta em Selvíria (MS). Revista Brasileira de Ciência do Solo. Viçosa, v.25, p.669-707, 2001.

Telles, D. D. Drenagem. In: Módulo 2.3, Curso de Elaboração de Projetos de Irrigação. Brasília: ABEAS, 1988. 61p.
Vieira, S. R. Variabilidade espacial de argila, silte e atributos químicos em uma parcela experimental de um Latossolo Roxo de Campinas (SP). Bragantia, Campinas, v.56, n.1, p.181-190, 1997.

Vieira, S. R. Geoestatística em estudos de variabilidade espacial. Campinas: IAC, 1998. 53p.

Vieira, S. R.; Nielsen, D. R.; Biggar, J. W. Spatial variability of field-measured infiltration rate. Soil Science Society of American Journal, Madison, v.45, n.6, p.1040-1048, 1981. 